Received: 23/05/2019

Revision: 28/11/2019

Accepted: 02/12/2019

OnlineFirst:28/01/2020

\title{
Creating a Digital Writing Classroom: A Mixed Methods Study about a First-year Composition Tablet Initiative
}

\section{Tara Hembrough}

Assoc. Prof., Southeastern Oklahoma State University, USA, thembrough@se.edu

\section{Jerrica Jordan}

Assoc. Prof., Tarrant County College, USA, jerrica.jordan@tccd.edu

\begin{abstract}
Having a higher level of digital literacy can contribute to students' better outcomes in first-year composition. However, some underprepared and financially disenfranchised students may not have digital literacy skills nor own a portable computing device, such as a tablet, to engage their coursework. This three-year, mixed methods study of 292 first-year composition students and 46 instructors at a research university suggests that implementing an institutional initiative to offer students tablets and a digitized curriculum for first-year composition can facilitate many positive outcomes. At the study's university, a "Tablet Initiative" raised some students' digital-literacy proficiency levels, enabled their digital composition practices, and improved their course outcomes as they spent additional time both inside and outside of the classroom in reading course texts; researching their topic; planning, drafting, and revising their work; and conducting peer reviews of one another's essays. Surveys, interviews, and course observations indicate that for many students, the Tablet Initiative generated a writing-intensive, student-centered, classroom experience, with many students from underprepared or lower socioeconomic backgrounds depending on their tablets. The study's results have implications for teaching and learning with mobile digital devices in first-year composition.
\end{abstract}

Keywords: tablet computers, digital composition, student persistence, evaluation of educational technology, digital divide, first-year composition

\section{INTRODUCTION}

Our culture and its technologies are constantly evolving, as is the notion of literacy, affecting the course design and class objectives that writing program administrators (WPAs) and instructors formulate for first-year composition (FYC) students. According to a National Center for Teachers of English (NCTE) position statement (2013), today, a literate individual must have many "abilities and competencies, many literacies." To

Citation: Hembrough, T., \& Jordan, J. (2020). Creating a Digital Writing Classroom: A Mixed Methods Study about a First-year Composition Tablet Initiative. International Journal of Instruction, 13(2), 567-586. https://doi.org/10.29333/iji.2020.13239a 
build digital literacy, one must "develop proficiency and fluency with the tools of technology; build intentional cross-cultural connections and relationships . . . so to pose and solve problems collaboratively and strengthen independent thought; design and share information for global communities to meet a variety of purposes; create . . . and evaluate multimedia texts; [and] attend to the ethical responsibilities required by these complex environments" (2013). Additionally, the Council of Writing Program Administrators (2008) includes digital composition skills in FYC's course outcomes, with digital literacy involving reading, writing, and sharing multimodal texts in online contexts (see Cooper, 2007; Lankshear \& Knobel, 2008). People's literacies are connected to their past, their current place in the social grid, and their future potential (NCTE, 2013), yet because of a digital divide, not everyone has the same access to the resources to gain increased digitally literacy.

To address NCTE's mission to promote digital literacy amongst students with diverse backgrounds, including underprepared and socio-economically disadvantaged students, the study's university began a digital "Tablet Initiative," providing freshmen with a Dell Latitude 10 tablet PC (TPC) and etexts for many required first-year (FY) courses, including FYC. Nationwide, the study's university represented the first to issue students TPCs, even though others had distributed iPads. As with other institutions offering digital initiatives, the study's university sought to draw students with a TPC that they could implement in active and collaborative learning environments, including the FYC classroom, due to the TPC's portability, easy internet access, and lower price compared to laptops. The Tablet Initiative's goal was to provide students of varied backgrounds with a more equitable degree of technological access, allowing them to achieve academic goals. The initiative involved the Departments of English, Speech Communication, Curriculum and Instruction, and Mathematics.

With the English Department's integration of TPCs, etexts, and a digital curriculum into Composition I and II, Author 1, the WPA, and Author 2, a graduate instructor and departmental staff member, engaged in a longitudinal study to assess the initiative's results upon students. As part of the curricular changes, the department created a rhetoric and style manual, as well as digitized course readers made available through the learning management system (LMS) via a course fee. Students also received printed copies of textbooks. The TPCs themselves offered Microsoft Office, unique mobile apps, and wireless connectivity and video conferencing. FYC instructors were given TPCs, etexts, and printed texts, and the department trained and encouraged them to implement TPCs in daily instruction. Previous to the initiative, students had only printed options of customized texts, and anecdotal evidence showed that only two-thirds purchased them, while others relied on sharing or utilized the Library's reserve copies. Moreover, many students did not own laptops or TPCs and were restricted to composing work at computer labs.

What would happen when all entering freshmen received a tablet to utilize in FYC, however? This question motivated the study's investigation of the TPC's incorporation into FYC, section-wide, over multiple years. Undertaking a mixed methods study, the authors examined how TPCs affect students' classroom writing habits. As research foci, the authors asked these questions: How would TPCs impact students' digital 
composition practices, especially those who were underprepared or financially disadvantaged? Could TPCs help students to address an array of FYC assignments and outcomes?

\section{CONTEXT AND REVIEW OF LITERATURE}

Digital literacy represents a key tenet of digital citizenship, with people having home internet access and utilizing the web daily (Mossberger, Tobert, \& McNeal, 2007). The digitally literate consider questions of genre, networked device, and ethics concerning their composition for and engagement with online communities (2007), as users implement "a range of modalities enabled by digital tools" (O'Brien \& Scharber, 2008, p. 67). Thus, conversations about digital literacy affect FYC's goals and curriculum. Describing the "refiguring [of] writing, teaching, and learning through wireless and mobile technologies," Johndan Johnson-Eilola and Stuart Selber (2009) highlight the "changing shapes" of composition involving implementing multiple devices for writing. However, instead of replacing familiar literacies, digital literacy is constructed upon them (Jenkins, 2008). Digital writing allows students to navigate new technologies and understand how varied digital writing contexts influence a text's message and reception (Hart-Davidson, Cushman, Grabill, DeVoss, \& Porter, 2005).

Selber has investigated how "students can play a more active role in the construction and reconstruction of technological systems" (2009, p. xi), and Teddi Fishman and Kathleen Blake Yancey (2009) ask instructors to teach composition via the digital devices that students already prize. Nonetheless, some students continue to be affected by a digital divide, in which the population is separated by socio-economic level and technological aptitude in utilizing digital technologies. Those having low-incomes and living in rural areas, as well as African-Americans and Hispanics, have diminished internet use-levels (U.S. Census, 2014), as well as lacking access to digital technologies, such as TPCs, at school and home (Dahlstrom \& Bichsel, 2011). Those with a reduced access to digital communication forums may lack relevant information, a means of interaction, or an audience for their work (Reynolds \& Lewis, 1997). Furthermore, a study between minority students with computer access and those without revealed better educational outcomes for the experimental group (Fairlie, 2012). Comparable to the digital divide, the participation gap denotes a variance in digital abilities amongst people possessing differing access to digital technologies (National Education Association, 2008).

Because of the digital divide's continued existence, Selber (2009) calls upon WPAs and writing faculty to teach computer literacy as part of their composition coursework. Students can gain functional, critical, and rhetorical literacy in becoming users, questioners, and producers of technology. Indeed, students report that they enjoy and gain greater knowledge in courses having digital components (Dahlstrom \& Bichsel, 2011). Amy Hea (2009) calls attention to the "difficult issues of integration, use, and development" involved in implementing mobile and wireless technology in the composition classroom (p. 10). Nonetheless, Melinda Turnley (2009) asks for WPAs and instructors to locate positive instances of anywhere, anytime learning involving digital devices in writing classes. Computer-supported classrooms promote a "studio 
approach," treating writing as "an activity," as opposed to "an object of study," with teachers helping students to compose work during class (Hochman \& Palmquist, 2009). Compared to traditional classrooms, in computer-supported classes, students stay ontask more often, work together with teachers more frequently, and collaborate amongst themselves to a greater extent. Additionally, teachers rely more on student-based activities as opposed to lecturing, with students directing their own learning. Overall, in computer-assisted classes, students feel surer of their writing skills and view composition-related activities as being vital to classroom practices. Furthermore, in laptop classrooms, students engage with "a flexible learning space," experience the "decentering effects" of a student-based atmosphere, and "extend the classroom" by utilizing portable laptops within and beyond it (2009).

The availability of mobile devices, such as tablets, may promote students' digital practices (Hea, 2009), and instructors describe specific possibilities that TPCs offer in their courses. First, teachers enjoy the wireless classroom's ability to provide students with "access to digital resources," including Google Docs, for composing and to create an organizational system, where students could post and refer to their assignments, as well as classmates' pieces being workshopped. Teachers also appreciate the wireless classroom for the ability to "intervene" as students compose or participate in research, to "demonstrate" to students the writing practices they should undertake, and to create "engagement" between students and their work. Next, students with computers can complete in-class assignments, while teachers work with them on all parts of the writing process, from invention through revision (Takayoshi \& Huot, 2009, p. 102-103; Sullivan, 2013). Finally, mobile computer labs can facilitate collaboration, as students move around to work together, utilizing their devices easily (Bemer, Moeller, \& Ball, 2009; Miller-Cochran \& Gierdowski, 2013).

Recently, a number of institutions have offered TPC, portable device, or laptop initiatives involving lower-level writing courses. In FYC classes, Oberlin College introduced an iPad program (Rice, 2011), and at Luther College, students utilized iPads to foster an inclusive atmosphere in which they could collaborate and write while accessing the LMS and electronic sources (Sullivan, 2013). Likewise, at Connecticut State University, students explored the benefits of engaging in a classroom with laptops as opposed to desktops (Hochman \& Palmquist, 2009), while at North Carolina State University, students implemented laptops via a "bring your own technology" initiative, since there were not enough computer classrooms to accommodate all FYC sections (Miller-Cochran \& Gierdowski, 2013). In a second-year writing classroom, students utilized laptops to facilitate their "writing processes" similarly (Takayoshi \& Huot, 2009 , p. 94). While important studies, the authors do not explore the benefits of providing students with TPCs that they may keep and utilize outside of the classroom for course purposes. In Miller-Cochran's and Gierdowski's (2013) study, students with devices were grouped together in sections, while those without their own technology took FYC together in computer classrooms. With this scenario, the authors were "concerned about isolating students who did not have their own laptops" (p. 51).

Some students from financially impoverished backgrounds may not possess the ability to purchase a portable computing device for higher education, suggesting an audience for 
offering a university digital initiative. At the College of Brockport, freshmen honors students participating in an iPad offering implemented their iPads almost daily, with $69 \%$ indicating that their acceptance of the Honors Program was due to the plan (Maxwell \& Banerjee, 2013). These students' reportage suggests that many identify the requisite for owning a TPC or other portable computer in college in order to succeed. Across the country, students show an increasing desire to use digital technology for academic purposes (Wu, Yen-Chun, Chun-Yu, Hao-Yun, Che-Hung, \& Sih-Han, 2012), with a larger number bringing TPCs to class (McHaney, 2011). 25\% of students nationwide own TPCs (Desantis, 2012), and in one university study, $72 \%$ of those having TPCs used them daily, with $86 \%$ accessing them for educational purposes (Cassidy, Colmenares, Jones, Manolovitz, \& Shen, 2014). Based on such trends, a university initiative might cater to some students' technologically-based preferences by offering them TPCs for engaging in FYC coursework.

Descriptive and preliminary results of teachers' implementation of tablets, iPads, and laptops into the composition classroom suggest their capacity to advance various writing objectives. Yet, the authors present no FYC studies involving course-wide implementations of tablet-related technologies detailing students' digital technology preferences. Moreover, few studies depict the ways students utilize TPC-related technology to address a range of FY writing assignments. Thus, interrogating the study's Tablet Initiative as a curricular design model whose outcomes have been contingent upon some local factors, the authors explore students' digital technology preferences and investigate the ways they utilized TPCs to complete FYC assignments. To a lesser extent, the authors also consider the support levels offered by teachers, as well as staff and administrators, and the deployment challenges. Lastly, by addressing the TPC's implementation as an avenue for promoting digital literacy in both underprepared and financially disadvantaged students, the mixed methods study addresses a critical gap concerning these populations' needs and preferences. As outcomes, the authors found that some students, including a subsection from underprepared or lower socioeconomic backgrounds, implemented TPCs to engage their FYC coursework. Specifically, students built upon their pre-existing knowledge of digital technology, merged their more familiar keyboarding skills with the TPC's greater technology, learned how to implement their TPCs in the current classroom with their instructor's help, and utilized their TPCs instead of going to the computer lab in order to read texts, conducted research, typed notes, composed work, engaged with a class LMS, collaborated with others, and utilized email.

\section{METHOD}

\section{Purpose}

Having Institutional Review Board approval, Author 1 created the study as an exploratory, mixed methods study (Cresswell \& Cresswell, 2017) involving the design model of a FYC, two-course sequence, as an exploratory study offers a learning opportunity for researchers (Schutt, 2014; Shields \& Rangarjan, 2013), and a mixed methods study allows an issue to be contemplated via multiple research phases and multiple types of methods (Cresswell \& Cresswell, 2017). Concerning the study's aims 
or purpose, the authors investigated how the incorporation of TPCs would affect students' engagement patterns with FYC. Specifically, the authors desired to determine how the initiative might help students to address an array of FYC assignments and outcomes by utilizing digital composition practices to hone their reading, analytical, and writing skills.

\section{Institutional Context and Curriculum}

The authors conducted the study at a Midwestern, public, comprehensive research university serving the state's lowest income counties. The university serves urban and rural students. Most students are state residents; $48 \%$ are minorities, mainly AfricanAmerican and Hispanic; and half of freshmen represent first-generation students. On average, freshmen enroll in 14.5 hours, with a GPA of 2.49 out of 4.0. Nearly all students are under the age of 25 , but $10 \%$ also live off-campus, forming a nontraditional student population often without access to computers or books at home. As a related issue affecting students' potential for academic success, some students come from higher income brackets and possess greater access to digital technologies useful to engaging FYC than their peers. Connected to such factors, the freshmen retention rate is $69 \%$, compared to $61 \%$ nationally (Tizon, 2016). Hence, compared with retention levels overall, the university's rate is "average," indicating that more can be done to help students matriculate. One element impacting students' graduation rates is that some, who fail FYC, leave college altogether. At the study's institution, an average of only $78 \%$ of students pass Composition I, but for those who fail it initially, their chances of passing subsequently drop. Moreover, students experiencing difficulty in FYC also face obstacles in their major classes. Of FY offerings, passing FYC is the largest indicator in predicting graduation (Garrett, Bridgewater, \& Feinstein, 2017). Overall, it remains vital for teachers to fashion assignments, including writing tasks, matching students' needs and values.

At the university, entering freshmen usually take Composition I and II. In Composition I, students engage with a range of academic writing genres, and in Composition II, students learn about argument-based, researched writing. Both courses involve a process-oriented approach to composition, with students revising many unit drafts and reflecting on their compositional methods. In Composition I, students compose a literacy narrative, advertisement analysis, rhetorical analysis, and literature review. They then compile a portfolio and write an introduction piece reflecting on their work. In Composition II, students pose a controversial question, which they seek to address through related essays presenting a scaffolding for a larger argumentative paper. In both courses, students also take an essay exam. For FYC's reading component, students interact with a reader containing academic texts exemplifying the genres they may encounter in other classes, as well as a rhetoric and style manual. For Composition I and II, the author formulated a standardized syllabus, set of prompts, and course schedule with reading and assignment due dates, which the instructors followed. Additionally, to make the Composition I and II sections as similar as possible in order to assess students' outcomes, the instructors graded each student's working and final essay drafts in accordance with departmental rubrics. 
Taking into account scholars' conversations about composing in digital environments, the authors considered how FYC's curriculum might be structured effectively to include digital components. In Composition I and II, because both courses require some of the same texts, the authors saw the value in asking students to pay the course fee for their books and technology fee for their TPC that was lower than the combined cost of print books for FYC and other participating FY courses alone. The authors also believed that FYC students possessing TPCs would benefit from the ability to participate electronically in the courses' in-class writing and drafting activities. As for the teachers, FYC is taught mostly by graduate instructors with diverse teaching and digitally-related technological experiences. To assist them in learning about their TPCs, the digital curriculum, and the online platforms, the English Department and the Center for Teaching Excellence (CTE) provided training sessions and pedagogical discussions.

Over a three-year period, the initiative evolved in important ways. Initially, TPCs did not include a keyboard, hindering students' typing ability and limiting the TPC's functionality for a broader range of uses necessary for composing in FYC. This context led Author 1 to request that students receive TPCs with external keyboards the following year. Then, after the initiative's last year, the university provided students with a voucher for the technology they preferred from a list of brands and products, including a TPC or credit toward a laptop. This last alteration gave students greater choice in selecting their favored device. Nevertheless, CTE's Director believed that users' experiences also improved over the years, as Dell's technology became more responsive.

\section{Research Methods}

Exploratory research and a mixed methods study were utilized. Exploratory research is conducted in order to obtain new perceptions, gain new ideas, and widen the knowledge of a phenomena (Schutt, 2014; Shields \& Rangarjan, 2013). A mixed methods study involves utilizing both quantitative and qualitative research methods, as "one data source alone is insufficient, results need to be explained, exploratory results need to be further examined, a study needs to be enhanced through adding a second method, [and] a theoretical stance needs to be advanced through the use of both types of methods" (Cresswell \& Cresswell, 2017, p. 60). Quantitative research deals with formal, objective information about the world, with mathematical quantification, and can be utilized to test relationships (Given, 2008), while qualitative research engages with phenomena that are impossible to quantify mathematically, including meanings, beliefs, symbols, and attributes (Babbie, 2014).

A mixed methods explanatory design was utilized with a multiphase combination timing consisting of three distinct phases, with quantitative research followed by qualitative research (Morse \& Neihaus, 2009). Researchers can implement multiphase combination timing when they employ multiple phases that include sequential and/or concurrent timing over a program of study. In each phase of the study's design, the authors first collected and analyzed the quantitative data. Then, second in the sequence, the authors collected and analyzed any qualitative data to help explain the quantitative results obtained. The qualitative data is constructed upon the quantitative data, and the two 
datasets are connected in the study's intermediate stage. The basis for this approach is that the quantitative data and their succeeding analysis provide a basic understanding of the research problem. The qualitative data and their analysis assist in illuminating those quantitative results by viewing participants' ideas in greater depth (Creswell \& Cresswell, 2017; Rossman \& Wilson, 1985; Teddlie \& Tashakkori, 2009).

To gather data, the authors utilized instruments, including student surveys, as well as instructor surveys and interviews. Furthermore, the authors performed classroom observations to create field notes as part of their participant observers' role. The surveys provided quantitative data (Merriam, 1998), and the interviews (Boyce \& Neale, 2006) and classroom observations (Bernard \& Bernard, 2012) gave qualitative data. For the surveys, the researchers posed a series of Likert-style questions, with answers ranging from 1 "strongly disagree" to 5 "strongly agree." Additionally, some questions were open answer to allow for student commentary (Allen \& Seaman, 2007). For the interviews, the researchers utilized semi-structured questions to give a small number of participants the opportunity to discuss their ideas on a particular topic, program, or situation, and through the interviews, the instructors were able to elaborate upon their survey answers (see Boyce \& Neale, 2006).

The authors assessed the Tablet Initiative at three stages linked to the study's three distinct phases: through an introductory evaluation in the first semester, a follow-up analysis in the second semester, and an appraisal two years afterwards. The first semester, the authors investigated the initiative's preliminary results through CTE's campus-wide survey of 434 students and a survey of 79 Composition I students and 35 instructors. The English Department also interviewed 6 of the teachers surveyed, who used TPCs regularly in the classroom. In the second semester, the authors completed a follow-up study by giving 218 Composition II students a survey, while 11 instructors also took a survey. The final year, the authors evaluated the TPC program's outcomes by interviewing 7 instructors, 2 of whom had served additionally as technology helpdesk assistants and 3 of whom participated in initial interviews. The authors also interviewed CTE's Director, heading the initiative's technical aspects. During all semesters, classroom observations were also conducted. Thus, during Phases 1 and 2, both quantitative and qualitative research methods were employed, and in Phase 3, only qualitative research methods were utilized. In filing data, the authors gave participants pseudonyms and kept the list of pseudonyms and associated names in a passwordencrypted file.

The first semester, the students surveyed were from 10 randomly chosen Composition I sections, and all represented freshmen. Students were administered a Likert-scale-based, post-survey and also encouraged to note their experiences regarding the initiative, specific to Composition I, through an open-ended question. Additionally, to provide demographic information, students noted their technology preferences, access to technology, and engagement with it for educational purposes. Instructors completed a similar survey concerning how TPCs functioned in the classroom, how students responded to the initiative, and how it affected teaching methods. Moreover, CTE's Director also surveyed university students separately through Likert-scale questions concerning their general TPC experiences and asked them to identify how their 
instructors utilized TPCs in class, if at all, through an open-ended question. Then, to identify more detailed patterns of instructor and student TPC engagement, the authors interviewed the FYC instructors via semi-structured interviews. The second semester, Composition II students engaged a follow-up survey similar to Composition I's, and the authors gathered data from half of the sections, with $90 \%$ of students $(n=208)$ representing freshmen, and $96 \%(n=210)$ continuing from the fall. Moreover, the Composition II teachers took a survey similar to the first one. Finally, the last year, the authors contacted FYC instructors and CTE's Director to make a cumulative assessment of the initiative. As in the first interview sequence, the authors presented questions concerning teachers' and students' implementation of TPCs and digital course material.

To provide for flexibility and adaptation, the study applied a constructivist grounded theory methodology to formulate themes in the data linked to the research questions as an analysis technique (Strauss, 1987; Strauss \& Juliet, 1994). A grounded theory method may begin with a question, or a collection of qualitative data, with codes being created from the data. Hence, grounded theory differs from the traditional research model, where researchers selects an existing theoretical framework, and only then collects data to indicate how the theory does or does not apply to the phenomenon under study (Allan, 2003). Having gathered the study materials, the authors assessed them in conjunction altogether once the study was completed. Namely, the authors utilized students' surveys, instructors' survey and interview materials, and the classroom observation field notes to discern trends concerning students' digital technology preferences, as well as the Tablet Initiative's effect upon students' composition practices and outcomes. The author analyzed the data relevant to the study's setting, participants, and chronology (Cresswell \& Cresswell, 2017) through a coding process and, based upon the study's research questions, considered emergent themes linked to students' digital technology-related, reading and writing practices. Then, relying on existing literature concerning the subject, and the themes determined during the study, the authors utilized an analytical framework to connect the data and build a storyline (Yin, 2009) about the study's setting, participants, and chronology in order to generate a description of the tablet program's details (Cresswell \& Cresswell, 2017), as linked to the authors' general research question concerning whether students would benefit from utilizing tablets in FYC.

To offer credibility to the study's claims, the authors were immersed in prolonged field engagement (Cresswell \& Cresswell, 2017), contemplating the research questions over a long period (Cresswell \& Miller, 2000). Additionally, the authors utilized the process of data triangulation by implementing "multiple sources of data" and "multiple methods to confirm the [study's] emerging findings" (Merriam, 1985, p. 204), as triangulation "seeks convergence, corroboration, and correspondence of results from the different methods" (Greene, Caracelli, \& Graham, 1989). By selecting an exploratory, mixed methods study; utilizing surveys, and conducting interviews by employing a constructivist grounded theory (see Strauss \& Juliet, 1994), the authors followed the protocols of other researchers reviewed to ensure that the research design was appropriate and the methodology consistent with the practice. 


\section{Sample Demographics}

Altogether, 79 Composition I students, 218 Composition II students, and 46 instructors participated in the study.

\section{FINDINGS}

As study outcomes, FYC students benefited from the Tablet Initiative by building upon their pre-existing knowledge of digital technology, merging their more familiar keyboarding skills with the TPC's greater technology, learning how to implement their TPCs in the current classroom with their instructor's help, and utilizing their TPCs instead of going to the computer lab in order to read texts, conduct research, type notes, compose work, engage with a class LMS, collaborate with others, and utilize email.

\section{Composition I Students' Digitally-Related Backgrounds and the Tablet Initiative}

The initiative's first semester, entering students possessed varying experiences with handheld digital devices and digitized curricula that arguably affected their FYC writing approaches, with students who had previous experiences with digital technology benefitting from it. Besides the university-issued TPC, some Composition I students surveyed also owned laptops $(74 \%, n=53)$, desktop computers $(6 \%, n=4)$, and personal TPCs $(1 \%, n=1)$. Moreover, CTE discovered that $41 \%(n=198)$ of students overall owned iPhones, while 29\% $(n=142)$ had Android phones. Because many students brought devices to campus, the authors gathered that they were at least somewhat familiar with the web, as well as many computing devices that might allow them to engage successfully with the initiative. Gauging students' attitudes toward digital technology remained valuable, however. Overall, $2 \%(n=8)$ avoided digital technology, including handheld digital devices; $12 \%(n=58)$ implemented it when necessary; $16 \%(n=75)$ used it when available; and 51\% $(n=246)$ integrated it daily. Whatever students' attitudes were toward digital technology, many had implemented it in their previous education. In Composition I, only 9\% of students $(n=7)$ had enrolled in an online class, a figure that makes sense, given that students were freshmen. Nevertheless, $78 \%(n=61)$ had taken a class with "technological components," suggesting that they engaged with technology in high-school classes in some aspect, arguably contributing to their more effective engagement with TPCs in FYC.

According to Composition I students surveyed, $83 \%(n=65)$ learned about their TPCs in their core courses, providing a foundation for the TPC's implementation that built upon students' potential prior existing digital technological experiences. Moreover, 50\% $(n=39)$ attended an orientation for their TPC and university-related platforms, and CTE reported that $38 \%(n=183)$ found the online tutorials provided to be helpful. In CTE's survey, 53\% of students $(n=256)$ indicated that the amount of difficulty they experienced using their TPC initially as being "none" to "some." Still, $50 \%$ of Composition I students $(n=39)$ reported that their instructor "used class time to teach them about the TPC," while 97\% $(n=74)$ recounted that their teacher was "able" and "willing to assist with TPC questions," and 96\% $(n=75)$ relayed that their instructor "provided aid" with LMS and online curriculum issues. 


\section{FYC Students' Reception of Tablets}

In CTE's survey, students commented on the TPC's quality, their likes or dislikes, and difficulties encountered. Regarding the TPC's value, $47 \%(n=228)$ responded positively to its quality, $66 \%(n=321)$ to its battery life, and $45 \%(n=217)$ to its responsiveness rate. Moreover, $37 \%(n=179)$ found Windows to be "easy to use." Students listing the TPC's pros appreciated its compact, sturdy, and lightweight nature; portability; navigability; and convenient uses, comparing it to a laptop. Many noted that having a tablet allowed them to complete school work regardless of their location, and others were glad that the TPC was included in their school technology fee and paired with etextbooks at a decreased cost. Finally, a few mentioned that their TPC provided an alternative when their personal computing device failed or was stolen. Overall, students who preferred to use digital technology but did not possess their own digital computing devices or have easy access to computer labs appreciated the tablets especially.

Despite the TPC's positively described attributes, $63 \%$ of students $(n=304)$ also discussed problems they faced with it, while others did not see the benefit of using it in their education. The conflicts that students encountered with the TPCs included freezes/lockups $(52 \%, n=254)$, wireless connectivity issues $(62 \%, n=301)$, lack of software $(18 \%, n=89)$, incompatibility with classroom materials $(17 \%, n=84)$, difficulty typing $(49 \%, n=236)$, and other issues $(12 \%, n=60)$. Of FYC students surveyed, 23\% $(n=66)$ experienced technical difficulties with their TPC ten or more times, and 55\% ( $n=161)$ visited the university tech help desk. Such problems may have caused some students to use their TPC less often or for fewer purposes, especially in addressing FYC curriculum. In such cases, many students chose to use their own personal computing devices or the labs, or to handwrite their work. Comparably, CTE reported that only $26 \%(n=125)$ of students felt that TPCs made their study time more efficient, and 27\% $(n=132)$ indicated that TPCs had become part of their learning routine. In Composition II, students reported only slightly higher results for these descriptors, with $36 \%(n=77)$ believing TPCs made studying more efficient, and $37 \%$ $(n=78)$ contending that TPCs structured their learning. These mixed reviews suggest that not all FY students wanted to implement TPCs as per their learning styles.

Nonetheless, even over the first year, FYC students and their instructors reported students' growing engagement with TPCs. The first semester, CTE found that 5\% of students $(n=25)$ utilized their TPCs an estimated 7 to 9 hours a week, and $11 \%(n=$ $54), 10$ hours plus. Altogether, that fall, $81 \%$ of students $(n=391)$ utilized their TPC at least weekly. During the first year, the authors surveyed students similarly to identify how often they brought their TPC to FYC classes. The second semester, the authors saw a rise in the number, up from $11 \%$ of Composition I students to $61 \%$ in Composition II using TPCs daily (see table 1). Indeed, 66\% of Composition II students $(n=140)$ reported that they liked implementing TPCs in class. According to CTE, one student argued, "It was useful in class [to have] to do a variety of different assignments." See table 1 for the survey results concerning the amount of time that Composition I and II students utilized their tablets in the classroom during the study's first year according to both the students and their instructors. 
Table 1

FYC Student/Instructor Survey for How Often Students and Instructors Utilized Tablets in the Classroom in the Study's First Year

\begin{tabular}{llrrr}
\hline & daily & weekly & monthly & never \\
\hline Composition I students & $50 \%$ & $21 \%$ & $8 \%$ & $22 \%$ \\
Composition I instructors & $46 \%$ & $9 \%$ & $15 \%$ & $31 \%$ \\
Composition II students & $61 \%$ & $14 \%$ & $7 \%$ & $8 \%$ \\
Composition II instructors & $18 \%$ & $9 \%$ & $18 \%$ & $55 \%$ \\
\hline$N=79$ Composition I students & & &
\end{tabular}

$N=79$ Composition I students

$N=218$ Composition II students, and $N=46$ instructors

Many students, especially those without their own personal computing devices or easy access to computer labs, reported positive instances of TPC usage. In CTE's survey, one student argued that her Windows calendar app kept her organized, and many remarked that they depended on their TPC exclusively for educational activities. One student insisted that a TPC "can be used anywhere, especially when there's no laptop or desktop around to use. [It] makes getting homework done a lot easier." Others found that having the TPC replaced their need for a laptop or visiting the lab. Another contended, "I like to use the tablet daily. I use this for about everything. It's basically my PC." While students utilized their TPCs at different rates, they also accessed them for diverging educational purposes. In FYC, over $50 \%$ of students reported using TPCs for conducting research, accessing Library search engines, checking course emails, finding an advertisement for a unit essay assignment, reading course texts, and submitting assignments (see table 2). Many of these outcomes mirror students' instances of TPC, iPad, or laptop usage discussed in the literature. On a related note, $63 \%$ of FYC students $(n=183)$ believed that teachers implemented TPCs appropriately in the classroom, even if some reported low application rates for some pedagogical purposes. Furthermore, $77 \%(n=225)$ found the online course materials provided via the curriculum to be helpful in reinforcing and supplementing instruction, as did $50 \%$ of instructors $(n=23)$. See table 2 for the survey results concerning the activities for which the Composition I and II students utilized their tablets in the classroom during the first year according to both the students and their instructors.

Table 2

FYC Student Survey for How Student/Instructor Implemented Tablets in Class in the Study's First Year

\begin{tabular}{lcc}
\hline & Composition I & Composition II \\
\hline Engaging tablet materials/LMS/course module & $50 \%, n=39$ & $20 \%, n=42$ \\
Homework assignments & $39 \%, n=31$ & $36 \%, n=76$ \\
In-class assignments & uncalculated & $9 \%, n=19$ \\
Draft work & uncalculated & $33 \%, n=70$ \\
Discussion boards & uncalculated & $3 \%, n=7$ \\
Peer editing & uncalculated & $8 \%, n=17$ \\
Conducting online research & $53 \%, n=42$ & $33 \%, n=70$ \\
Accessing Library search engines & $53 \%, n=42$ & $36 \%, n=76$ \\
Checking course emails & $60 \%, n=47$ & $33 \%, n=71$ \\
Viewing coursework or homework schedule & uncalculated & $23 \%, n=48$ \\
Finding online advertisement for analysis for essay draft & $54 \%, n=43$ & $34 \%, n=72$ \\
Reading course texts/articles on LMS & $61 \%, n=48$ & $39 \%, n=83$ \\
Submitting papers or assignments & uncalculated & $68 \%, n=144$ \\
Checking grades & uncalculated & $6 \%, n=14$ \\
\hline
\end{tabular}

$N=79$ Composition I students

$N=218$ Composition II students 
Comparatively, in CTE's survey, students, providing short-answer commentary, also reported utilizing TPCs for FYC purposes, such as conducting research, reading course texts, completing in-class assignments, engaging in journal writing and freewriting, peer editing, and essay drafting.

\section{Ways in Which FYC Students Engaged Their TPCs}

During the initiative, as outcomes, the authors found that some FYC students utilized their own, privately purchased devices or visited the computer labs, and others preferred more traditional methods - namely handwriting - for composing work. However, a subsection of students from underprepared or lower socioeconomic backgrounds also embraced and benefited from the TPCs. Engaging their tablets prompted underprepared students to merge more familiar keyboarding skills with the TPC's newer technology to achieve greater digital literacy, and having their own device for composing provided students without personal computers or TPCs a means of engaging the FYC coursework.

\section{Interacting with TPCs before the External Keyboard Became Standard}

From the FYC teachers' view, because the university TPC did not include an external keyboard the first year, not as many students composed work on it as in subsequent ones. Initially, many students relied on the TPC as an ereader for digital texts and online materials instead, with some using TPCs to take notes on readings and classwork via the touch screen. CTE found that $45 \%$ of students $(n=218)$ read etexts or accessed other classroom tools via their TPCs, while in FYC, $61 \%$ of Composition I $(n=48)$ and $39 \%$ of Composition II students $(n=83)$ surveyed read course texts on TPCs.

\section{Composing through Different Practices}

Although the first year, some students relied on their TPCs mostly for reading practices, according to CTE, 35\% $(n=170)$ also utilized the Microsoft Office software, and in CTE's and our surveys, many students reported typing work in some form on their device. In FYC, $10 \%$ of teachers $(n=5)$ surveyed urged students to implement their TPCs for in-class writing, and in Composition II, 9\% of students $(n=19)$ surveyed did so, while another $33 \%(n=70)$ utilized TPCs to draft essay work. Within the classroom, charging issues linked to the lack of adequate outlets for all, students' forgetfulness in bringing their TPCs, and some instructors' limited engagement with TPCs generated obstacles to more students utilizing TPCs. Yet even during the first semester, some students bought keyboards to type work, while others used the TPC's internal keyboard itself. Justine, an instructor interviewed in the second semester, reported that her students implemented their TPCs, utilizing either internal or external keyboards "to compose essays" on "workshop or peer-review days." Similarly, Thu-Ha, both an instructor and a Writing Center administrator, specified that FYC students brought their TPCs to the Center to draft work with tutors. In CTE's survey, one student, commenting on the TPC's value, explained, "I do not have a laptop so it is very nice to have a portable computer. I bought a keyboard for it so I can actually type papers." Furthermore, a veteran taking Composition I communicated that his TPC allowed him to work in the comfort of home and avoid the stress associated with crowded locations. Not having a computer, he had gone to a lab previously, a situation that made composing essays difficult. 
During the initial year especially, some students relied on TPCs to compose work, while others preferred typing on laptops or even writing by hand to create longer pieces in class. Interestingly, in the first semester, the consensus among instructors interviewed was that students were excited about having TPCs and would have used them more willingly and frequently for composition activities if they had come with an external keyboard that year. At the initiative's outset, the problems that some students encountered with composing on TPCs included engaging the screen/touch feature and navigating the on-screen keyboard, which made it take a long time to type work. Consequently, Thu-Ha explained that her students carried TPCs "in their backpack[s]" for many course-related purposes but wrote with laptops. Likewise, Justine reported that her students brought TPCs to class but would have preferred accessories that came standard with them as well, such as a keyboard and mouse set. To aid in composition practices, some Composition II students did purchase TPC-related items, including a keyboard $(12 \%, n=25)$, mouse $(8 \%, n=17)$, and stylus $(6 \%, n=13)$.

The mixed results concerning students' reactions to composing work on TPCs without external keyboards touch upon other studies. At Luther College, students liked typing work on the iPad's touchscreen instead of bringing their heavy laptops to class, if they had them (2013, p. 2). Nonetheless, at Oberlin College, some FYC students reported that their iPads were a "hindrance" in "drafting papers" (Rice, 2011). The tablet's virtual keyboard does not allow users to position their fingers in a resting state, and the compact nature of the TPC's onscreen keyboard means that users must type in a smaller area. These factors cause students accustomed to traditional keyboards to type at slower speeds (Davis, Orr, Kong, \& Chow-Hong, 2015). Additionally, TPC users must switch between screens displaying alpha characters and numeric and symbolic ones, which can cause typing mistakes. Still, user knowledge of and "flexibility with devices" can override these drawbacks to the virtual keyboard (2015), as the authors saw with students at their locale.

While some students preferred to compose by means other than the TPC, and others met with TPC complications, a few lacked training for their devices or did not possess TPCs at all. Naomi, interviewed in the second semester, reported that some students were unfamiliar with TPC technology, while others did not possess their TPCs on some days because they were waiting for a replacement because of breakage. Moreover, the first year, two instructors interviewed reported that one or two students, who had not received TPCs, were placed on a waiting list. Lastly, a few students, who were not freshmen, did not receive TPCs through the initiative, even though the university offered them for a rental fee. While the initiative was supposed to provide all students with the same access to technology for better success in FY courses, such "glitches" and policies prevented this fuller outcome. Because of students' differing contexts, when Naomi offered work days, she told students to "bring whatever they felt more comfortable working on." Since Matthew, interviewed in the second semester, was located in a computer classroom, he, too, gave students multiple options for composing documents. Similarly, $78 \%$ of Composition II students $(n=167)$ reported that instructors offered them a choice of using TPCs, alternative devices, or no devices to engage with classroom writing activities, with $12 \%(n=25)$ finding this question to be inapplicable. 
The second and third years, incoming students received TPCs with external keyboards, and the number who composed with them in FYC rose, since having TPCs was "more convenient" and students could type "much faster" than before, Thu-Ha explained in a subsequent interview. According to Thu-Ha and the other teachers interviewed in the final year, students engaged in prewriting and drafting, wrote summaries, worked collaboratively, and completed exams with their tablets. Cami, another teacher, reported that students preferred using TPCs on in-class work once they could make direct changes to their digital drafts simply, while Anna argued that with the keyboard added, "It was easy to ask students to use the tablets for classroom activities."

\section{Utilizing the Tablet for Research, Collaboration, and Other Reasons}

Teachers and students utilized TPCs in multiple FYC-classroom contexts associated with their composition processes, including conducting online research, collaborating, and connecting to the class grid. $35 \%$ of instructors $(n=16)$ surveyed specified that students conducted in-class internet research utilizing TPCs, while at $43 \%$ of Composition I and II students $(n=112)$ surveyed reported implementing them for online investigations. Adam claimed that students were excited about utilizing Google or the Library's website to gather information. Additionally, Justine's students utilized TPCs to access the LMS to compose a class blog, while Thu-Ha's class logged onto the university's computer-system hard-drive, on which students stored files on personal accounts. As another purpose, students utilized TPCs for collaboration and peer review. According to CTE, $20 \%(n=95)$ surveyed believed TPCs helped them to interact with classmates. Of instructors, $42 \%(n=4)$ interviewed engaged the tablet for peer review and other collective activities, while $19 \%$ of Composition II students $(n=40)$ surveyed reported implementing TPCs in concerted ways. Justine's students, completing in-class group work with TPCs, enjoyed having the option to compose either on Word processing documents and then submit them to the LMS or compose directly in online assignments. Likewise, Anna's students found that TPCs helped with many activities, including "freewrites, drafting, researching, and commenting on live Google Docs while doing in-class revisions." Lastly, in Composition I and II, 46\% of students $(n=139)$ implemented TPCs to check emails, while in Composition II, 23\% $(n=48)$ viewed coursework and $68 \%(n=144)$ submitted assignments.

\section{Identifying Tablet Alternatives}

While students and teachers described obstacles to implementing the Tablet Initiative, some also critiqued the device that the university chose and questioned whether tuition money could have been better spent elsewhere. The study's TPC represented a firstedition model, and its newness factor proved problematic, as it might for any new edition, according to CTE's Director. As a separate issue, some students already owned portable devices or would have preferred to receive other handheld devices, such as iPads. Matthew specified that his students "wanted to have the option of using [their] own, better tablet," and in the FYC surveys, some students also commented on their preference for a laptop. Regardless, many students gave favorable reviews to CTE, with one claiming, "I like [the tablet] better than an iPad because it's easier to use." 


\section{DISCUSSION}

Many instructors and students felt that the Tablet Initiative was successful in that it assisted many students enrolled in FYC in addressing their coursework. As study findings, FYC students benefited from the initiative by building upon their pre-existing knowledge of digital technology, merging their more familiar keyboarding skills with the TPC's greater technology, learning how to implement their TPCs in the current classroom with their instructor's help, and utilizing their TPCs instead of going to the computer lab in order to read texts, conduct research, type notes, compose work, engage with a class LMS, collaborate with others, and utilize email. Additionally, during the initiative, students' overall pass rates in FYC rose an average of at least $4 \%$.

\section{FYC Student Outcomes}

FYC instructors implemented TPCs for various classroom assignments, with $46 \%$ ( $n=$ 23) surveyed believing they integrated TPCs appropriately or well. Some felt discouraged after encountering technical difficulties with the university wi-fi, the TPC itself, and/or online course platforms, and others argued that they spent too much time teaching students to navigate their TPCs at the expense of covering course-related material. Nonetheless, since the initiative's initial semester, instructors interviewed believed that time had alleviated many TPC-related technical problems, as well as implementation issues. Moreover, by the second year, Thu-Ha also found that her students were more familiar with their TPCs than their predecessors had been and used them more often to compose work. Indeed, as findings contributing to the literature, we determined that during the initiative, some FYC students utilized their own devices or visited the labs, and others preferred to handwrite their work. However, engagement with their tablets prompted some underprepared students to achieve greater digital literacy, and having their own device for composing provided students without personal computers or TPCs a means of engaging the coursework. Mobile devices, including tablets, create "unique structural demands on writers" affecting their writing processes (Jones, 2008, p. 264), yet students implemented TPCs successfully in numerous ways.

Concerning FYC student outcomes, which the initiative arguably affected, $95 \%$ of Composition I students $(n=72)$ surveyed identified "class assignments to be appropriate in meeting course objectives," and 96\% $(n=73)$ believed the class helped them "build foundational writing skills." Likewise, in Composition II, $85 \%$ of students $(n=183)$ surveyed identified course assignments to be beneficial and reported the class provided them with "knowledge about composition and research processes." These results indicate that most students found FYC to be valuable, whether or not they implemented their TPCs. In conjunction with the initiative's results, the authors also considered grade outcomes and discovered that since the first semester, the pass rate over the initiative's timespan rose an average of $5 \%$ for Composition I and $4 \%$ for Composition II. While multiple factors impacting students' outcomes must be considered, arguably, the Tablet Initiative supported some students in undertaking their coursework, which they could engage anywhere and at any time. 


\section{RECOMMENDATIONS, LIMITATIONS, AND CONCLUSION}

Scholars have asked how the task of giving all students "equitable access to technology" can be accomplished (Walker, Blair, Eyman, Hart-Davidson, Mcleod, Graybill, ... . Tulley, 2011), as the "conditions of access have a substantial effect of people's acquisition and development of digital literacy" (Selfe \& Hawisher, 2004, p. 644). From the Tablet Initiative's outset, the authors did not believe that the it would facilitate all, or even a majority of, students' preferred composing styles. Neither did the authors foresee that all students would utilize the university TPCs for their coursework. Still, the authors viewed the TPCs and FYC's digitized curriculum as additional offerings to facilitate students' academic achievement. Moreover, the authors recognized that the initiative was a work-in-progress. As academic outcomes that assisted the FYC students in achieving success in these classes, they spent additional time both inside and outside of the classroom in reading their course texts; researching their topic; planning, drafting, and revising their work; and conducting peer reviews of one another's essays. For students, doing well in FYC is important, as those who pass these classes successfully usually do well in their other courses. Additionally, for students to be retained at the university, passing their classes during the first year is the most important factor in their having the best chance to graduate.

As a study limitation, the authors did not ask students about their racial background as a potential factor affecting their socioeconomic status, given the university's political climate. However, future studies should address these factors.

That being noted, the authors would like to offer WPAs and instructors a piece of advice that may prove helpful in implementing a tablet program like this one to facilitate students' digital composition of work. Institutions should consider giving students options about the hardware they receive in order to accommodate their interests, comfort levels, and prior hardware acquisitions. Indeed, administrators and teachers should implement digital technology "to expand or enhance students' involvement in technology planning and decision making" and "meet students' expectations for anytime, everywhere, Wi-Fi access on the devices they prefer to use" (Dahlstrom \& Bichsel, 2011).

At the study's university, many students were receptive to using TPC technology in aiding their reading and writing processes and lowering the costs of texts and hardware. Still, at the study's locale, more work must be done to facilitate digital initiatives, including bolstering the university's technological infrastructure and supporting teacher training. In the end, addressing the digital divide involves more than just offering students technological devices and platforms to help them succeed in the moment; it means having bigger discussions about socio-economic divides (Amiel, 2006; Gunkel, 2003; Warschauer, Knobel \& Stone, 2004). However, as a means of promoting social justice in one instance, the Tablet Initiative addressed students' digital technology requisites for engaging more successfully with the FYC classroom, thus providing greater continuity in FY students' educational experiences. By gaining access to online curriculum and the web via TPCs, students could engage with FYC coursework and compose work in a manner best suited to their learning style and preference. 


\section{REFERENCES}

Allen, E., \& Seaman, C. (2007). Likert scales and data analyses. Qual Prog, 40, 64-65.

Amiel, T. (2006). Mistaking computers for technology: Technology literacy and the digital divide. AACE Journal, 14(3), 235-256.

Babbie, E. (2014). The basics of social research. Belmont: Wadsworth Cengage.

Bernard, H. R., \& Bernard, H. R. (2012). Social research methods: Qualitative and quantitative approaches. Los Angeles, CA: Sage.

Bemer, A., Moeller, R., \& Ball, C. (2009). Designing collaborative learning spaces: Where material culture meets mobile writing processes. Progr. Persp, 1(2), 139-166.

Boyce, C., \& Neale, P. (2006) Conducting in-depth interview: A guide for designing and conducting in-depth interviews for evaluation input. Pathfinder International Tool Series, Monitoring and Evaluation-2. Retrieved from pathfind.org/site/DocServer/m_e_tool_series_indepth_interviews.pdf?docID=6301.

Cassidy, E., Colmenares, A., Jones, G., Manolovitz, T., \& Shen, L. (2014). Higher education and emerging technologies. Journal of Academic Librarianship, 40(2), 124-133. doi.org/10.1016/j.acalib.2014.02.003.

Cooper, M. (2007). Learning digital literacies. In C. Selfe (Ed.), Multimodal composing: Resources for teachers (pp. 181-186). Hampton P.

Council of Writing Program Administrators. (2008). WPA Outcomes statement for first-year composition. Retrieved from Wpacouncil.org/positions/outcomes.html

Cresswell, J. \& Creswell, D. (2017). Research design: Qualitative, quantitative, and mixed methods approaches. SAGE

Cresswell, J., \& Miller, D. (2000). Determining validity in qualitative inquiry. Theory into Practice, 39(3), 124-130.

Dahlstrom, E., \& Bichsel, J. (2011). ECAR national study of undergraduate students and information technology, 2011 report. Educause Center for Analysis and Research.

Davis, L., Orr, A., Kong, X., \& Chow-Hong, L. (2015). Assessing student writing on tablets. Educational Assessment, 20(3), 180-198.

Desantis, N. (2012). Tablet ownership triples among college students. Chronicle of Higher Education. Retrieved from www.chronicle.com/blogs/wiredcampus/tablet-ownershiptriples-among-college-students/35764.

Fairlie, R. (2012). Academic achievement, technology and race: Experimental evidence. Ec. of Education Review, 31(5), 663-679. doi.org/10.1016/j.econedurev.2012.04.003.

Fishman, T., \& Yancey, K. Learning unplugged. (2009). In Amy Hea (Ed.), Going wireless: A critical exploration of wireless and mobile technologies for composition teachers and researchers (pp. 35-52). New York: Hampton.

Garrett, N., Bridgewater, M., \& Feinstein, B. (2017). How student performance in first-year composition predicts retention and overall student success. In Todd Ruecker (Ed.), Retention, persistence, and writing programs (pp. 93-113). Utah: SUP.

Given, L. (2008). The SAGE encyclopedia of qualitative research methods. Los Angeles, CA: SAGE Publications. 
Gunkel, D. (2003). Second thoughts: Toward a critique of the digital divide. New Media \& Society, 5(4), 499-522.

Hart-Davidson, B., Cushman, E., Grabill, J., DeVoss, \& D., Porter, J. (2005). Why teach digital $\quad$ writing? $10(1) . \quad$ Retrieved from kairos.technorhetoric.net/10.1/coverweb/wide/introduction.html.

Hea, A. (2009). Introduction. In Amy Hea (Ed.), Going wireless: A critical exploration of wireless and mobile technologies for composition teachers and researchers (pp. 1-14). New York: Hampton.

Hochman, W., \& Palmquist, M. (2009). From desktop to laptop: Making transitions to wireless: Learning in writing classrooms. In Amy Hea (Ed.), Going wireless: A critical exploration of wireless and mobile technologies for composition teachers and researchers (pp. 109-132). New York: Hampton.

Jenkins, H. (2009). Confronting the challenges of participatory culture: Media education for the 21st century. Cambridge, MA: MIT.

Johnson-Eilola, J., \& Selber, S. (2009). The changing shapes of writing: Rhetoric, new media, and composition. In Amy Hea (Ed.), Going wireless: A critical exploration of wireless and mobile technologies for composition teachers and researchers (pp. 15-34). New York: Hampton.

Jones, J. (2008). Patterns of revision in online writing: A study of Wikipedia's featured articles. Written Communication, 25(2), 262-289. doi.org/10.1177/0741088307312940.

Kvavik, R. (2005). Convenience, communications, and control: How students use technology. In D. Oblinger \& J. Oblinger (Eds.), Educating the net generation (pp. 7.17.20). Educause.

Lankshear, C. \& Knobel, M. (2008). Digital literacies: Concepts, policies and practices. Lang.

Maxwell, P., \& Banerjee, P. (2013). Nature and extent of iPad use among freshmen honors students. J. of Edu Technology Systems, 42(1), 21-38. doi.org/10.2190/ET.42.1.c

McHaney, R. (2011). The new digital shoreline. Sterling, VA: Stylus.

Merriam, S. (1998). Qualitative research and case study applications in education. JosseyBass.

Miller-Cochran, S., \& Gierdowski, D. (2013). Making peace with the rising costs of writing technologies: Flexible classroom design as a sustainable solution. Computers and Composition, 30(1), 50-60. doi.org/10.1016/j.compcom.2012.12.002.

Morse, J. M., \& Niehaus, L. (2009). Mixed methods design: Principles and procedures. Walnut Creek, CA: Left Coast Press.

Mossberger, K., Tolbert, C., \& McNeal, R. (2007). Digital citizenship: The internet, society, and participation. Cambridge, MA: MIT.

National Council of Teachers. (2013). Position statement: The National Council of Teachers definition of 21st century literacies. Retrieved from www.ncte.org/positions/statements/21stcentdefinition.

National Education Association. (2008). The participation gap: A conversation with media expert and MIT professor Henry Jenkins. Retrieved from www.nea.org/home/15468.htm. 
O'Brien, D., \& Scharber, C. (2008). Digital literacies go to school: Potholes and possibilities. J of Adolescent and Adult Literacy, 52(1), 66-68. doi10.1598/JAAL.52.1.7

Reynolds, T., \& Lewis, C. (1997). The changing topography of computer access for composition students. Computers and Composition, 14(2), 269-278.

Rossman, G. \& Wilson, B. (1985). Numbers and words: Combining quantitative and qualitative methods in a single large-scale evaluation study. Eval. Rev, 9(5), 627-643.

Rice, A. (2011, October 18). Colleges take varied approaches to iPad experiments, with mixed results. Chronicle of Higher Education. Retrieved from www.chronicle.com/blogs/wiredcampus/author/arice/page/3

Schutt, R. (2014). Investigating the social world: The process and practice of research. $8^{\text {th }}$ ed. Los Angeles, CA: Sage.

Selber, S. (2004). Multiliteracies for a digital age. Carbondale, IL: Southern Illinois U.

Selfe, C., \& Hawisher, G. (2004). Literate lives in the information age: Narratives of literacy from the United States. Lawrence Erlbaum, New Jersey.

Shields, P., \& Rangarjan, N. (2013). A playbook for research methods: Integrating conceptual frameworks and project management. Stillwater, OK: New Forums Press.

Strauss, A., \& Juliet, C. (1994). Grounded theory methodology: An overview. In N. Denzin \& Y. Lincoln (Eds.), Handbook of qualitative research (pp. 273-284). Thousand Oaks, CA: Sage.

Sullivan, R. (2013). The tablet inscribed: Inclusive writing instruction with the iPad. College Teaching, 6(1), 1-2. doi.org/10.1080/87567555.2012.700339.

Takayoshi, P., \& Huot, B. (2009). Composing in a digital world: The transition of a writing program and its faculty. WPA, 32(3), 89-119.

Teddlie, C., \& Tashakkori, A. (2009). Foundations of mixed methods research. Thousand Oaks, CA: Sage.

Tizon, C. (2016). Snapshot report-persistence and retention. National Student Clearinghouse. Retrieved from https://nscresearchcenter.org/snapshotreport-persistenceretention22/.

Turnley, M. (2009). Reterritorialized flows: Critically considering student agency in wireless pedagogies. In A. Hea (Ed.), Going wireless: A critical exploration of wireless and mobile technologies for composition teachers and researchers (pp.87-108). NY: Hampton.

U.S. Census. (2014). Computer and internet use. Retrieved from www.census.gov/topics/population/computer-internet.html.

Walker, J., Blair, K., Eyman, D., Hart-Davidson, W., Mcleod, M., Graybill, J., ... Tulley, C. (2011). Computers and composition 20/20: A conversation piece, or what some very smart people have to say about the future. Computers and Composition, 28(4). doi:10.1016/j.compcom.2011.09.004.

Warschauer, M., Knobel, M, \& Stone, S. (2004). Technology and equity in schooling: Deconstructing the digital divide. Educational Policy, 18(4), 562-588. Doi:/abs/10.1177/0895904804266469.

Wu, W., Yen-Chun, J., Chun-Yu, C., Hao-Yun, K., Che-Hung, L., \& Sih-Han, H. (2012). Review of trends from mobile learning studies: A meta-analysis. Computers \& Education, 59(1), 817-827. doi.org/10.1016/j.compedu.2012.03.016. 